\title{
DALCÍDIO JURANDIR: Marajó não é o centro do mundo
}

\section{DALCÍDIO JURANDIR: Marajó is not the center of the world}

\section{FURTADO, Marli Tereza.}

Doutora em Teoria e História Literária pela Universidade estadual de Campinas.

Docente da Universidade Federal do Pará.

E-mail: marlitf@ufpa.br

ORCID ID: https://orcid.org/0000-0001-7597-7834

\section{COSTA, Regina Barbosa da.}

Doutora em Estudos Literários pela Universidade Federal do Pará.

Docente da Secretaria de Estado de Educação do Pará.

E-mail: anygger@yahoo.com.br

\section{RESUMO}

Ao iniciar a produção e publicação do ciclo romanesco denominado Extremo Norte, com o romance Chove nos campos de Cachoeira, em 1941, o marajoara Dalcídio Jurandir (1909/1979) quebrou a protagonização da selva na literatura que figurava a Amazônia, o que poucos autores haviam realizado até então. Além de se utilizar de técnica inovadora, como a análise mental, o monólogo interior, Jurandir localiza a saga do menino Alfredo, afrodescendente, personagem central do ciclo, entre os anos vinte e trinta do século passado, com retrospectivas a dados e fatos anteriores a essa década. Chama a atenção, nessa primeira obra do ciclo, como nas demais, o número de textos citados, ou referidos, ou amalgamados ao enredo das obras. Esse entrecruzar de textos que perpassam o ciclo (composto de dez obras) demonstra o leitor Dalcídio Jurandir, que, antes de escritor, se iniciara jornalista e crítico literário para periódicos. Nosso propósito, neste texto é analisar o entrelaçamento da voz do crítico literário, com a voz do narrador e com a voz de personagens leitores, nos três primeiros romances do ciclo, a saber: Chove nos campos de Cachoeira (1941), Marajó (1947), Três casas e um rio (1958), para demonstrar que a obra de Dalcídio Jurandir, de forte conotação social, apesar de focalizar, nesses primeiros romances o espaço marajoara, amplia a percepção desse espaço ao leitor ao se abrir para a recepção de obras de diferentes gêneros e nacionalidades. Jurandir cita textos literários e textos da tradição oral para realçar o caráter romanesco de sua saga.

Palavras-chave: Dalcídio Jurandir; crítico literário; leitor; romances. 


\section{ABSTRACT}

By starting the production and publication of the novel Extremo Norte, with the novel Chove nos Campos de Cachoeira, in 1941, the marajoara Dalcídio Jurandir (1909/1979) broke the role of the jungle in the literature that featured the Amazon, which few authors had performed until then. In addition to using innovative techniques, such as mental analysis, interior monologue, Jurandir locates the saga of the boy Alfredo, of African descent, the central character of the cycle, between the twenties and thirties of the last century, with retrospectives to data and facts prior to this decade. In this first work of the cycle, as in the others, the number of texts cited, referred to, or amalgamated to the plot of the works draws attention. This interweaving of texts that pervade the cycle (composed of ten works) demonstrates the reader Dalcídio Jurandir, who, before becoming a writer, had started out as a journalist and literary critic for periodicals. Our purpose in this text is to analyze the intertwining of the literary critic's voice, with the voice of the narrator and with the voice of reader characters, in the first three novels of the cycle, namely: Chove nos campos de Cachoeira (1941), Marajó (1947), Três casa e um rio (1958), to demonstrate that the work of Dalcídio Jurandir, with a strong social connotation, despite focusing on the Marajoara space in these first novels, expands the reader's perception of this space by opening up to the reception of works of different genres and nationalities. Jurandir cites literary texts and texts from the oral tradition to highlight the novelistic character of his saga.

Keywords: Dalcídio Jurandir; literary critic; reader; novels.

Dalcídio Jurandir Ramos Pereira nasceu em Ponte de Pedras, no Marajó, em 1909, e morreu no Rio de Janeiro, em 1979, cidade onde residiu desde 1941, ano marcado pela primeira edição do romance Chove nos campos de Cachoeira, publicado pela editora Vecchi, que, juntamente com o jornal Dom Casmurro, o premiara no ano anterior e cujo dinheiro the possibilitou a mudança para a então capital federal.

Se enquanto romancista, o autor apareceu no cenário nacional apenas em 1941, no cenário de Belém, durante a década de 1930 e início da de 1940, marcou seu lugar na imprensa contribuindo para periódicos locais, como poeta, articulista, crítico literário, repórter e cronista. Seus textos encontram-se n' O Estado do Pará, n'A Folha do Norte, na Revista Escola, n'A Semana, em Novidade, em Guajarina e em Terra Imatura.

Enquanto procurava acertar-se profissionalmente em um emprego, o que se consolidava era a carreira de jornalista. Alguns de seus textos, ainda em trinta, foram publicados fora de Belém, como a crítica ao romance São Bernardo, de Graciliano Ramos, editado pela Revista Acadêmica, do Rio, em 1935. Em Belém, aparecem textos de crítica literária sobre poemas de Raul de Leoni, de Henrique Carstens e Odylo Costa Filho; sobre livros de Artur Cezar Ferreira Reis, José Lins do Rego (sobre Riacho Doce (abril/junho de 
1940); Érico Veríssimo (O arranha-céu e o lírio dos campos, agosto de 1938); Osvaldo Orico (seu discurso na Academia, agosto de 1938); nota sobre Machado de Assis e Machado Coelho (julho de 1939); sobre Nunes Pereira ( $A$ presença de Bahira, abril de 1941$)$; sobre o livro de Emil Farah, Cangerão; e sobre o teatro do Estudante de Joraci Camargo, junho de 1941.

Esses textos citados já demonstram a gama de leitura do autor e o tipo de leitor que era: um leitor crítico que escrevia sobre as obras que lia para que sua opinião incidisse sobre a do leitor dos periódicos. Entretanto, cabe assinalar como a " biblioteca sem muros" (COSTA, 2019) de Jurandir já era extensa e mais se estendeu nessa década fundamental para a formação literária do autor e suas primeiras tentativas no literário, quer como poeta ou como ficcionista, que escreveu crônicas, contos e romances. Nessa década, ele escreveu e reescreveu Chove nos campos de Cachoeira e a primeira versão de Marajó, que veio a público somente em 1947.

Já chamamos a atenção em texto sobre o autor (FURTADO e COSTA, 2014) a respeito dos livros que ele solicitou à esposa Guiomarina, para ler nos períodos em que esteve preso nos anos de 1936 e 1937, por sua atuação esquerdista na Aliança Nacional Libertadora. Entre os livros solicitados estão Dom Quixote de La Mancha, Fausto, de Goethe e O negro brasileiro, de Artur Ramos.

Renard Perez, em Escritores brasileiros contemporâneos (1. a edição de 1960), dedica um capítulo a Dalcídio Jurandir e faz um traçado biográfico dele entremeando sua vida de leitor e de literato até aquele ano da publicação de Belém do Grão-Pará, quarto livro da série do Extremo Norte, iniciada, então, com o livro premiado em 1941. Perez chama a atenção para o papel de Rainero Maroja, (ex promotor público de Cachoeira do Arari, no Marajó) que, em Belém, emprestava livros ao jovem e por meio de quem conheceu autores portugueses como Fialho de Almeida, Antônio Feliciano de Castilho, Antônio Nobre, além dos poetas brasileiros Augusto dos Anjos e Cruz e Souza (PEREZ, 1964, p. 91).

Destacamos que na crítica sobre São Bernardo, de 1935, Jurandir cita Machado de Assis, Tristão de Ataíde e faz referência a Stendhal e na crítica de 1941, sobre o teatro de Joraci Camargo, remete à dificuldade de se fazer teatro, no Brasil, naquele momento em que o "grosso público se encontrava envenenado pelo grosso cinema, pelos fascículos de Irmã Branca, pelo Ardel, pela própria ignorância de teatro". Irmã Branca é uma alusão ao filme de mesmo nome, de Victor Flemming, EUA, 1933, sobre o qual circularam fascículos, e Henri Ardel, pseudônimo masculino de Berth Palmyre Victorine, cujos romances circularam no Brasil principalmente entre 1940 e 1960, publicados na coleção Biblioteca das Moças, da Cia Editora Nacional.

Esses dois textos nos servem de parâmetro para demonstrarmos como o crítico literário Dalcídio Jurandir conhecia a trilha entre o fazer 
literário "de elite" (teatro de Pirandello, por exemplo) e o fazer literário de multidão (o teatro de Romain Rolland, citado por ele), mas, por outro lado, mostram um literato que se construía questionando os caminhos entre a arte de massa e a arte "de uma educação sentimental", para citar Stendhal, mas sem pieguice. Parece que Dalcídio Jurandir procurava um caminho de a arte ser útil sem camisas de força, em qualquer direção.

Esse escritor que procurava um caminho escreve dois títulos iniciais de sua obra, ainda na década de 1930, conforme já adiantado: Chove nos campos de Cachoeira e Marajó. Os dois romances seguem para o prêmio, sendo o primeiro premiado e publicado em seguida e o segundo, reelaborado e publicado em 1947 . Dalcídio Jurandir, então, anuncia uma saga de dez romances a partir de seu terceiro livro Três casas e um rio (1958). No entanto, mais tarde, em entrevistas inclui os dois primeiros romances na saga que chega até o décimo e afirma que Chove nos campos de Cachoeira é o livro embrionário do ciclo, do qual saem todos os temas tratados nos nove romances que o seguem e cujos títulos são: Marajó (1947), Três casas e um rio (1958), Belém do Grão-Pará(1960), Passagem dos Inocentes (1963), Primeira manhã (1967), Ponte do Galo (1971), Os habitantes (1976), Chão dos Lobos (1976), Ribanceira (1978).

Já comprovamos esse embrionarismo do primeiro livro do ciclo (FURTADO, 2002; 2010) e, neste momento, vale assinalar que o protagonista do Extremo Norte, Alfredo, não aparece apenas no segundo romance do ciclo, embora os personagens circulem os mesmos locais e a paisagem seja a mesma dos outros romances.

Nesse momento, gostaríamos de comprovar mais um fio embrionário do romance inicial: as trilhas de leitura do autor Dalcídio Jurandir refletidas na criação de um universo ficcional, a princípio localizado na ilha de Marajó, cujos personagens dialogam com o universo por meio da leitura, seja de jornais, revistas, catálogos, poemas, romances, livros de História, de mitologia, textos de oratória, textos religiosos, a Bíblia, almanaques, livros de cordel, textos de teatro, textos orais, ou criados para a pantomima do bumba meu boi, ou repetidos da tradição oral.

No enredo de Chove nos campos de Cachoeira, localizado nos inícios dos anos de 1920, temos a presença de dois protagonistas: os meio irmãos Alfredo e Eutanázio. De Eutanázio temos o possível final de uma trajetória de melancolia, angústia, solidão, amor não correspondido, mas também de uma consciência embutida da corrosão do mundo em função da divisão dos homens em categorias dos que possuem e dos que nada possuem, dos letrados e dos não letrados, dos descompassos do favoritismo. Ele também vive o drama do poeta inconstituído, para nós aquele que tenta se fazer poeta, mas se encontra dividido entre o que agrada o povo não letrado, os versos do boi, por exemplo, e o que agradaria o público letrado, cujos 
modelos são os poetas já reconhecidos pela crítica, como os românticos e parnasianos.

De Alfredo, temos o drama do menino que quer se evadir daquele universo circunscrito que vivencia em Cachoeira, mas que repudia e, em meio a fantasias, criadas por meio do caroço de tucumã, elemento imbuído de simbologia local ${ }^{1}$ e carregado por ele como uma varinha mágica, sonha em ir estudar em Belém, símbolo de modernidade e ilusão de prosperidade. Alfredo vive o sonho de superação social via estudo. O subterrâneo do sonho não revela apenas vontade de evasão local e de ascensão social: mas de aceitação ou não de sua origem afro descendente, pois, diferente de Eutanázio, filho de pai e mãe brancos, ele é filho do branco major Alberto e da preta $d$. Amélia, com quem o major vive em segundas núpcias, mas sem ser casado, o que já revela o drama da inclusão social do negro na sociedade brasileira.

Na tese de doutorado, intitulada Dalcidio Jurandir: leitor e criador de persnonagens-leitores no Ciclo do Extremo Norte, defendida em 2019, Regina Barbosa da Costa faz, conforme o título indica, um levantamento exaustivo da prática de leitura dos personagens dos dez romances do ciclo, além de indicar as leituras de um narrador de terceira pessoa que aparece recorrentemente na obra.

Do primeiro livro, chamam a atenção as tipologias textuais que aparecem citadas direta ou indiretamente. Em tabela, Costa enumera 23 textos literários, divididos entre poemas, romances e um cordel; 21 textos diversos (desde catálogos, cartas, discursos, textos bíblicos); 4 textos teatrais; 4 romances folhetins; 9 periódicos. Ainda é citado o Chernoviz, metonímia de um dos livros de medicina de Pedro Luiz Napoleão Chernoviz².

Convém assinalar que a casa em que habitam os dois protagonistas, Alfredo e Eutanázio, o chalé de Major Alberto, pai de ambos, aparece como o núcleo maior de leitura e de leitores locais. No chalé, há uma saleta mobiliada com duas estantes, cheias de livros, uma mesinha com retratos do major Alberto com seus filhos, um retrato de Augusto Comte, uma santa Rita de Cássia, um relógio redondo, uma pasta com papéis municipais. Ainda na saleta há uma velha chapeleira negra e quatro cadeiras.

Conforme nos indica Roger Chartier (1996, p. 90-91), "o livro tradicionalmente representava "decoração" e a biblioteca sinal de um saber ou de um poder". No caso da biblioteca de major Alberto, composta pelos livros que são citados no decorrer da narrativa e que engloba obras canonizadas de poesia, de prosa e de teatro, além de revistas de agricultura importantes na época, como La Hacienda, ou Chácara e quintais, os livros

\footnotetext{
${ }^{1} \mathrm{O}$ caroço de tucumã, na tradição local, guarda o segredo da noite.

2 Médico polonês, que viveu um tempo no Brasil e editou mais de uma obra na área.
} 
não serviram de decoração, mas, no conjunto, reforçaram de certa forma a importância da família e lhe deram um certo poder local.

Desse núcleo de personagens, Major Alberto é o que se destaca como um propagador de leitura. Temos poucos dados de sua vida ilustrada, mas o suficiente para sabermos sobre seu gosto pela leitura, coroado por seu papel de tipógrafo, pois tinha em casa uma pequena prensa e se aventurou na criação de um jornal. Solicitava catálogos de diversos lugares do mundo, assinava coleção de revistas, era um homem conectado para além daquele universo.

Formou na leitura seus dois filhos, a ponto de Eutanázio, em seus desencontros existenciais, na adolescência, ter se encontrado como encadernador de livros. E Alfredo se deliciava entre os catálogos, os livros de História natural e as revistas agrícolas. Dona Amélia, quase analfabeta, é iniciada em leitura por meio das declamações de major Alberto e das pantomimas que ensaiava ao ler em voz alta os textos de que gostava.

Interessante, que Jurandir não coloca a escola como propagadora e ou legitimadora de leitura, pois ela aparece obtusa em figuras de mestres prepotentes, autoritários e arbitrários, a ponto de fazerem Eutanázio e Alfredo nela se calarem e cumprirem o estudo escolar apenas como um dever de ofício. Essa escola tão precária e excluidora intensifica em Alfredo o desejo de evasão daquele vilarejo; ela, a escola, não lhe abre horizontes, apenas o confrange e ele sonha com os colégios de Belém mais pelo contraste que eles representam do que pelo incentivo positivo da escola local.

Se major Alberto não só é respeitado e visto na vila de Cachoeira por sua atuação como secretário da Intendência local, mas por este poder de leitor, a Eutanázio é dado o poder de comunicação entre os enamorados locais e ele exerce o papel de escrevinhador de cartas ao par amoroso Ângela e João Galinha, jovens analfabetos que representam a chaga da miséria social e cultural da ilha de Marajó, até nos dias atuais conhecida como local de alto índice de analfabetismo no Pará.

Dalcídio Jurandir, para dar expressão a uma de suas indignações com a realidade brasileira da época, principalmente a miséria do analfabetismo, figura os adolescentes fora da escola obtusa que segregava e excluía e os coloca ao sabor de um terceiro que escrevia para Ângela como se fosse João e para João como se fosse Ângela, mas na realidade representando ele mesmo em sua revolta existencial.

Fazemos um parêntese para retomar a informação de que Dalcídio Jurandir participou do Primeiro Congresso Brasileiro de Escritores, acontecido em São Paulo, entre 22 e 27 de janeiro de 1945, no qual, além de representar a delegação do Pará, juntamente com Clovis Gusmão, Dante Costa, Eneida de Moraes e Nélio Reis, era da comissão de cultura e assuntos 
gerais. Nesse congresso, apresentou um texto-tese, em co-autoria com Astrogildo Pereira, em que propunha uma campanha nacional para liquidar 0 analfabetismo no Brasil. A tese foi aprovada pelos congressistas ${ }^{3}$.

Também é forte a presença de Eutanázio como poeta inconstituído, uma vez que é movido pelo desejo da criação poética a qual consegue traduzir em versos da pantomima do boi bumbá local. Ainda que o povo repita feliz seus versos, ele se sente frustrado por não conseguir criar poemas ao estilo dos modelos canônicos presentes na biblioteca do pai e pelo pai aclamados e declamados. Major Alberto tinha, inclusive, um poeta preferido, Gonçalves Dias, a quem se punha a defender como melhor poeta, em vez de Olavo Bilac, conforme lhe falaram. Ironicamente, o povo fruía os versos do boi, enquanto seu autor se martirizava por tê-los produzido.

Voltando aos leitores de Chove nos campos de Cachoeira, há outros leitores do cânone presentes na obra, como o doutor Campos, mas destacamos o leitor de folhetins Salu, dono da taverna, onde dividia seu tempo entre atender os fregueses e as leituras de obras do espanhol Henrique Perez Escrich, também do suposto espanhol Antonio Contreras e do francês Henri Ardel. Lia e relia desses autores, respectivamente: 0 manuscrito Materno (editado em três volumes); $A$ mulher adúltera (editado em quatro volumes); Rainha e mendiga (editado em quatro volumes) e $A$ dor de amar (editado em um volume).

Salu representa o leitor "intensivo", que lê intensivamente e o "romance dele apodera-se, o prende e governa" (CHARTIER, 1999) e Costa (2019) chama a atenção para o fato de Salu ser um migrante cearense em Cachoeira, rastreando a origem de sua preferência por folhetins na grande repercussão que, principalmente Escrich, teve no Ceará. Por outro lado, ela também assinala que havia uma dinâmica do comércio de livros em Belém, já no século XIX, o que se ratifica em Sales e Nobre (2009):

Na segunda metade do século XIX, a cidade de Belém, em decorrência da intensa imigração portuguesa, ocasionada pelo comércio e extração do látex, começava a intensificar seu mercado de livros. [...]a prática de impressão funcionava desde 1821, importava livros diretamente de Portugal e seu mercado livreiro aparecia representado em grandes catálogos como os de Garraux (SALES; NOBRE, 2009, p. 11-12).

Belém, portanto, era um centro difusor de leitura para o interior do estado, mas também as personagens de Cachoeira transitavam entre a ilha e a capital, tanto que, em Belém, Eutanázio vê um livro que deseja ler: a

${ }^{3}$ Ver MOTA, Carlos Guilherme. Ideologia da Cultura Brasileira (1933-1974). São Paulo: Ática, 1977. 
dor do mundo, possível alusão ao texto de Arthur Schopenhauer, As dores do mundo, de 1850.

Salu é um leitor tão devotado e enfronhado intensivamente em suas leituras que chega a ser roubado em sua venda, sem sequer perceber 0 momento do roubo. Interessante que ele decora os enredos dessas obras e os reconta, a seu modo, a outras pessoas de seu universo, a ponto de 0 narrador o considerar "um homem fabuloso" (JURANDIR, 1941, p. 245). Em vários momentos da narrativa, ele é focalizado contando para alguns segundos leitores os romances lidos. No final de Chove nos campos de Cachoeira, enquanto aguardam a possível morte de Eutanázio, na saleta, Salu se faz autor do romance da Rainha e mendiga, contando baixinho a outra personagem essa saga.

Em seu segundo romance da série, Marajó, publicado em 1947, conforme já dito, Jurandir continua o retrato do universo amazônico marajoara, com um diferencial: ele localiza sua narrativa em extensas fazendas, próximas da Vila de Ponta de Pedras, com um grupo de personagens diferentes do livro anterior, divididos entre os donos das terras, representados pelos poderosos Coutinhos e alguns comparsas, e o grupo de pobres trabalhadores locais que erram pelas fazendas e vilas. Esta narrativa é a única das dez do ciclo em que Jurandir focaliza de perto o latifúndio local responsável pelo cerceamento da população miúda, relegada a dois caminhos: pobreza e migração. A miséria local é bastante enfatizada, assim como a prepotência, os desmandos e a desfaçatez dos proprietários das grandes extensões de terra que sobrepujam o valor do homem em função do valor do gado.

Nesse universo fechado, circunscrito, aparece um número menor de personagens letrados e a praticar leituras. Costa (2019) traça uma tabela em que aparecem cerca de dez leitores cujas práticas de leitura se dividem entre literatura, diversos, periódicos e livros religiosos. Enquanto a Odisseia, de Homero, é citada via memória de Missunga, o filho do coronel, que relembra um de seus mestres do curso de direito, no Rio, personagens locais citam poema de Raimundo Correia, conto de Charles Perrault, contos de As mil e uma noites, Histórias do imperador Carlos Magno e o doze pares de França em meio a almanaques, como o Bristol, o César Santos, a periódicos, além de livros religiosos e espíritas. Interessante que sete periódicos são lidos ou foram lidos pelos personagens, entre eles a revista norte americana Time, ao lado d'O livro de São Cipriano ${ }^{4}$ e de histórias de Pedro Malazarte.

${ }^{4}$ O Livro de São Cipriano é uma compilação dos ensinamentos do grande mago, são Cipriano, bispo de Antioquia, nascido no século III, que passou para a história como um mártir e qanhou fama como o maqo mais conhecido do mundo. Seu livro traz, para as novas gerações, um pouco da história e do legado de um dos maiores nomes do ocultismo. (https://www.pallaseditora.com.br) 
Se por um lado os personagens leitores desse universo letrado demonstram terem lido as obras citadas, por outro, os personagens do povo contam e recontam histórias provenientes do imaginário social da região, dividindo-as com inúmeros reisados a diferentes santos. Vicente Salles (2001) fez a primeira recolha dessas histórias orais populares presentes na narrativa, assim como visualizou a incorporação no enredo da narrativa do rimance ibérico Dona Silvana (SALLES, 1978), história (re) vivenciada pela personagem Orminda.

É bom enfatizar que o representante mais expressivo dentre os personagens-leitores do romance é o excluído Ciloca, tocador de violão, expadeiro, que contraiu hanseníase. Revoltado, porque acossado pelo sentimento de rejeição, Ciloca tem vontade de vingança contra aquela sociedade que, na figura de um policial, o convocara a se recolher a um leprosário.

Tal como Salu e Major Alberto, da vila de Cachoeira, Ciloca não é somente um leitor, mas propagador de suas leituras, pois as reconta, inventando bastante, a um grupo de interlocutores formado pelos meninos pobres da vila de Ponta de Pedras. Suas leituras compreendem principalmente as narrativas de mistério e ocultismo, comédia e pornografia. Ainda são registrados como leituras suas o conto $A$ bela adormecida no bosque, de Charles Perrault, as histórias de As mil e uma noites, especialmente o conto Ali Babá e os quarenta ladrões, além de contos e lendas de feiticeiros, como a lenda amazônica do Pajé Sacaca os contos de meninos encantados. Vejamos o registro do narrador:

Ciloca contava amores que inventava, vícios que não tinha, padre que vira agarrado às devotas na sacristia, charadas d'O Malho que decifrara, bruxarias de São Cipriano que o livro do santo bruxo não contava. Falava de Pedro Malazarte e de proezas que 0 herói nunca fizera (JURANDIR, 1978, p. 41-42).

De certa forma, Ciloca parece incorporar as representações de suas leituras e ele é um pouco o bruxo de São Cipriano e um pouco Pedro Malazarte, dois heróis populares da antiheroicidade. Naquela sociedade, ele é temido pelos adultos devido a suas leituras de bruxaria, principalmente pelo Livro de São Cipriano, como se a prática dessa leitura o tornasse um iniciado na arte, mas é acolhido e respeitado pelo grupo de meninos, seus leitores-ouvintes, pelo encanto despertado por suas histórias.

Começava a lembrar os meninos um a um, Alcides, Pedrinho, Irval, curiosos dele, que não tinham medo, atentos e fascinados pelo que ele contava, e os pervertia. 
Contou certa vez uma história inteira das Mil e Uma Noites. Lera-a no livro nas madrugadas da padaria, o livro era de Sinhazinha. (JURANDIR, 1978, p. 262).

Nesse excerto não temos apenas a fascinação dos meninos pelo reconto de Ciloca, como a origem de certas histórias recontadas, cuja fonte estava em livros que lia.

Assim como as leituras, em seus recontos, o irmanavam aos meninos locais, por outro lado, Ihe davam visão do mundo a ponto de perceber a origem das agruras locais e a alienação humana que grassava naquele universo de tantos destituídos de bens materiais, de tantos destituídos do direito ao letramento. Suas leituras o ajudavam a resistir e seu grande ato de resistência se dá ao final, quando foge da vila, para não ceder à exigência do policial que o conduziria ao leprosário. Sua reflexão final demonstra sua consciência da função estética da arte e da fruição literária: "Que seria dos meninos que ouviam as histórias coçando as feridas, daqueles comedores de terra sem Pedro Malazarte, a Bela adormecida, os jantares na casa do rei que duravam a noite inteira?" (JURANDIR, 1978, p.262).

No caso de Ciloca, temos a leitura como elemento de inclusão social tanto para ele, que se inclui entre os meninos da vila, quanto para os meninos que exercitam o letramento e o mundo da leitura.

No terceiro livro da série, Três casas e um rio, de 1958, Dalcídio Jurandir volta a focalizar um núcleo de personagens do primeiro romance, localizados na vila de Cachoeira e arredores. Em função disso, alguns personagens ressurgem dentro do mesmo drama e da mesma configuração, tanto que Alfredo, o protagonista, continua a perseguir o sonho de estudar em Belém e seus pais, o major Alberto e dona Amélia, vivem seu cotidiano, ele como secretário da Intendência e ela, como dona de casa.

Dessa forma, repetem-se os nomes da comunidade de leitores locais, com destaque a Major Alberto, leitor de maior relevância, posto que dono dos livros da saleta de sua casa, orador e declamador de textos para a ouvinte dona Amélia, colecionador de catálogos provenientes da França, Inglaterra e Estados Unidos.

Na tabela elaborada por Barbosa (2019), com relação à presença de leituras na obra, aparecem no campo da literatura: livro de mitologia, os autores Walter Scott e Camilo Castelo Branco e a obra No país da arte, de Blasco Ibanez. Somam-se a estes vários periódicos, livros religiosos, inclusive fascículos sobre Santa Rita de Cássia; citação de óperas e do músico Caruso; e diversos, como: livros de Flamarion, o Chernoviz, 
dicionários, o Livro Felisberto de Carvalho(2.0 volume), utilizado, no mundo real, para a iniciação à leitura.

Major Alberto, nesse romance, passa a ser editor por meio do prelinho que já possuía no enredo da primeira obra e que vai para a saleta, organizada também como biblioteca. Ele edita o jornal $A$ gazetinha. Interessante cruzar este fato ficcional com a realidade. No mundo real, o Capitão Alfredo Pereira, pai do escritor Dalcídio Jurandir, fundou, em Cachoeira, o jornal A Gazetinha, em 1922. E no jornal encontra-se texto que fala da necessidade da leitura e da escrita para a renovação da sociedade e do crescimento do cidadão e da pátria:

Nesta vila de Cachoeira nota-se, presentemente, uma certa animação em mandarem-se os meninos para as escolas, o que até há poucos dias era objeto de completo e criminoso descaso por parte dos paes e dos responsáveis pela instrução dos seus filhos e apaniguados. (...) Para defensão da Pátria, tanto em terra, como no mar, é preciso, é imprescindível saber ler e escrever. ( $A$ GAZETINHA, ano 2, 1922)

O texto recorre a uma adjetivação pesada ("completo e criminoso) ao considerado descaso por parte dos pais ao não mandarem seus filhos para a escola. Alguns dados são demonstrados pelo jornal $A$ Gazetinha da vida real: Dalcídio Jurandir, como algumas de suas personagens, provinha de um pai letrado e leitor; sua iniciação ao jornalismo vem do berço; sua indignação contra 0 analfabetismo, de uma consciência precoce sobre a realidade local. Daí a "biblioteca sem muros" presente em sua obra.

Dois pontos ainda merecem ser realçados com relação à presença da leitura em Três casas e um rio. O primeiro liga-se a um encontro entre major Alberto e o pintor Raul em que se demonstra a vontade do primeiro em propagar conhecimentos e do segundo, as reflexões que passa a elaborar.

O próprio major Alberto, sempre em dúvida a respeito dos valores locais, mandou uma vez chamar o pintor NA Intendência. [...] Levou Raul ao chalé onde lhe mostrou catálogos de tintas, quadros e pincéis. A propósito da Itália, citou No país da arte, de Blasco Ibanez e representou na varanda, a cena em que Miguel Ângelo, na Capela Sixtina, pintando o Juízo Final, proibia a entrada do papa. Foi um dia de satisfação, mas, também, de 
insatisfações para Raul. Recolheu ao casebre com um suspiro: "Nós, os pobres, poderemos saber as coisas? Poderemos estudar o ofício que a gente escolher, que a natureza nos deu?" Cachoeira estava tão longe da Itália,da arte... Abriu um velho mapa, pousou o olhar e a indignação no Mar Mediterrâneo, na Itália... fechou o mapa com impaciência, levantando um pouco de poeira. (JURANDIR, 1994, p. 41, grifo nosso).

Raul se conscientiza de suas condições precárias e da dificuldade em chegar a uma técnica mais apurada na arte, vivendo naquele contexto. Assim como toma consciência das possibilidades de produção em centros mais avançados, também se conscientiza de que foi usado pelo Dr. Lustosa, na ampliação de seus domínios e na exploração e exclusão da população de Cachoeira, ao contratá-lo para pintar placas de proibição à entrada de pessoas comuns em suas propriedades. Refletindo sobre a necessidade do domínio da leitura em benefício geral para a não opressão e exploração, ele decide não pintar mais uma letra para o latifundiário. Major Alberto, de certa forma, alfabetizou Raul com relação ao poder da arte.

Decorre do encontro entre Major Alberto e Raul a importância dos catálogos em sua biblioteca. Se formos ao texto "Bibliotecas sem Muros", de Chartier (1999), perceberemos a importância do catálogo para a instituição de uma biblioteca aberta e universal:

Para quem quer erigir uma biblioteca aberta e universal, a propriedade de tais catálogos é uma necessidade. A soma de seus títulos define uma biblioteca ideal, liberada das fronteiras que impõe a coleção particular, ultrapassando os limites inerentes às coleções e compilações pela construção imaterial de uma espécie de bibliotecas das bibliotecas, na qual nada, ou quase nada, faz falta. (CHARTIER, 1999, p.73).

Guardadas as devidas proporções, não se esquecendo de que Chartier está trabalhando com a História das bibliotecas e não ignorando o lado comercial que os catálogos passaram a desempenhar no campo editorial, os catálogos de Major Alberto desempenham esse papel de biblioteca, ampliando a materialidade de suas duas estantes de livros, a ponto de seu filho Alfredo passar horas lendo-os, na saleta, e Raul ter expandido seu horizonte artístico na lição de Major Alberto, por meio deles.

Concluímos nossa reflexão considerando que a demonstração da presença recorrente de personagens leitores nos três primeiros romances do ciclo Extremo Norte, o núcleo marajoara da série, nos diferentes gêneros e veículos culturais, atesta o empenho de Dalcídio Jurandir em configurar 
Marajó em sua ficção não como um mundo amazônico perdido e isolado como comumente a região foi figurada. E a biblioteca do autor Dalcídio Jurandir, representada nesse universo de leitura, difere bastante da de muitos escritores que protagonizaram a Amazônia em sua ficção, focalizando especialmente a Amazônia gomífera e citando os viajantes e os paradigmas do início do século, Alberto Rangel e Euclides da Cunha. Diferentemente de seus antecessores que dialogavam com os dois autores citados e viajantes estrangeiros, para demonstrar cientificidade em suas obras, assim como uma forma de legitimar-se por meio de uma tradição literária, Jurandir cita textos literários diversos e textos da tradição oral para realçar o caráter romanesco de sua saga.

\section{REFERÊNCIAS}

CHARTIER, Roger. A ordem dos livros. Leitores, autores e bibliotecas na Europa entre os séculos XIV e XVII. Brasília: Editora Universidade de Brasília, 1999.

CHARTIER, Roger. (Org.). Práticas da leitura. São Paulo: estação Liberdade, 1996.

COSTA, Regina Barbosa da. Dalcídio Jurandir: leitor e criador de persnonagens-leitores no Ciclo do Extremo Norte. Tese de doutorado. Belém: UFPA, 2019.

FURTADO, Marli Tereza. Universo derruído e corrosão do herói em Dalcídio Jurandir. IEL, Unicamp, 2002, Tese de doutorado; Campinas: Mercado de Letras, 2010.

FURTADO, Marli Tereza; COSTA, Regina Barbosa da. O leitor erudito Dalcídio Jurandir e seus -personagens-leitores na ilha do Marajó. In: PEREIRA, Edvaldo; COSTA, Regina; BATISTA, Suellen; PINHEIRO, Veridiana. Textos e contextos literários: ensaios sobre literatura e memória. Curitiba: editora CRV, 2014.

GAZETINHA, ano 2, 1992

JURANDIR, Dalcídio. Chove nos campos de Cachoeira. Rio de Janeiro: editora Vecchi, 1941.

JURANDIR, Dalcídio. Marajó. Rio de Janeiro: Cátedra; Brasília, INL, 1978.

JURANDIR, Dalcídio. Três casas e um rio. Belém: Cejup, 1994.

MOTA, Carlos Guilherme. Ideologia da Cultura Brasileira (1933-

1974). São Paulo: Ática, 1977. 
PEREZ, Renard. Escritores brasileiros contemporâneos. Rio de Janeiro: editora Civilização Brasileira, 1964.

SALES, Germana Araújo; NOBRE, Izenete. Mercadorias e livros: entre fumo de rapé e aguardente, na Belém do século XIX. In: Moara, Belém, n. ${ }^{\circ}$ 32, p.11-29, jan-junho., 2009.

SALLES, Vicente. VII jornada do conto popular paraense. Narrador: Dalcídio Jurandir. Brasília: Micro Edição do Autor, 2001).

SALLES, Vicente. Chão de Dalcídio. In: JURANDIR, Dalcídio. Marajó. Rio de Janeiro: Cátedra; Brasília, INL, 1978.

https://www.pallaseditora.com.br (consultado em 10 de novembro de 2021)

Recebido em: 26/11/2021

Aceite em: 08/12/2021 